\title{
Accuray, Inc.: A Neurosurgical Business Case Study
}

John R. Adler Jr. ${ }^{1}$

1. Department of Radiation Oncology, Stanford University Medical Center, Stanford, CA, USA

$\square$ Corresponding author: John R. Adler Jr., jra@stanford.edu

Disclosures can be found in Additional Information at the end of the article

\section{Abstract}

Accuray Incorporated designs, develops and sells the CyberKnife Stereotactic Radiosurgery System, an image-guided radiosurgical instrument used to ablate diverse benign and malignant lesions. In 2001, Accuray received clearance from the Food and Drug Administration (FDA) to market the CyberKnife for radiosurgical treatment of lesions anywhere in the body where radiation is indicated. From its inception in 1994 until 2009, the CyberKnife has been used at more than 180 installations worldwide to treat more than 80,000 patients. This is the story of how a neurosurgeon conceptualized, developed, and implemented the CyberKnife idea, and the lessons I learned from founding and eventually managing a biomedical device company. Most people who hear this story are surprised to learn that so much of Accuray, Inc's formation was uncalculated. This should not really be surprising, given the typical young aspiring academic I was when this journey began.

Categories: Radiation Oncology, Miscellaneous, Neurosurgery

Keywords: cyberknife, accuray, Stereotactic Radiosurgery, entrepreneurship, image guidance, radiosurgery

\section{Introduction And Background}

Accuray Incorporated designs, develops and sells the CyberKnife ${ }^{\circledR}$ Stereotactic Radiosurgery System, an image-guided radiosurgical instrument used to ablate diverse benign and malignant lesions. In 2001, Accuray received clearance from the Food and Drug Administration (FDA) to market the CyberKnife for radiosurgical treatment of lesions anywhere in the body where radiation is indicated. From its inception in 1994 until 2009, the CyberKnife has been used at more than 180 installations worldwide to treat more than 80,000 patients.

This is the story of how a neurosurgeon conceptualized, developed, and implemented the CyberKnife idea, and lessons I learned from founding and eventually managing a biomedical device company. Most people who hear this story are surprised to learn that so much of Accuray, Inc.'s formation was uncalculated. This should not really be surprising given the

Published 09/15/2009

C) Copyright 2009

Adler. This is an open access article distributed under the terms of the Creative Commons Attribution License CC-BY 3.0., which permits unrestricted use, distribution, and reproduction in any medium, provided the original author and source are credited. typical young aspiring academic I was when this journey began.

\section{Review}

\section{Recognizing the problem equals opportunity}

Like almost any new venture, Accuray was built upon some basic assumption, which in my case was that whether surgeons liked it or not, surgery was destined to become increasingly less invasive. I detected the first glimmering of this notion in 1985 during a one-year infolded neurosurgical fellowship, which I spent (without a lot of forethought) studying at the 
Karolinska Institute in Stockholm. I quickly fell under the sway of the charismatic Lars Leksell and his neurosurgical team, who were developing new clinical applications for Leksell's radiosurgical brainchild, the GammaKnife. It was clear that the GammaKnife was a revolutionary concept for treating brain tumors. What I saw convinced me that radiosurgery would profoundly impact the treatment of nearly all types of brain tumors, even as it required neurosurgeons to call into question their very definition of surgery.

Being a young neurosurgeon with ambitions of being involved in the evolution of our specialty, and who, as an under-utilized fellow had far too much time on his hands, I pondered how I might contribute to a medical world in which radiosurgery might have a profound impact.

As I came to fully comprehend Leksell's enormous accomplishment, it also seemed apparent that it would be very hard to significantly improve upon his technology. The elegance of the GammaKnife stemmed largely from its elemental simplicity. However, this same design also severely restricted its potential for technological progress. Leksell himself was not blind to such limitations. Intellectually always restive and simultaneously committed to a world of even less invasive neurosurgery, Leksell was still actively exploring during my tenure at the Karolinska, even more benign concepts for radiosurgical targeting than the stereotactic frame that bore his name, e.g.,. Leksell oversaw the treatment of several GammaKnife patients in whom his stereotactic frame was anchored to a plaster helmet rather than the skull. While the GammaKnife made possible a near-magical procedure for ablating tissue in the brain, it also seemed obvious to me that the same radiobiologic principles could and should be clinically applicable to targets in the spine, chest or abdomen with comparable success. Imagining the extension of this new procedure throughout the body made it clear that the stereotactic frame was a fundamental limitation of the GammaKnife. While daydreaming in my Karolinska office, I came to realize that my recognition of this "problem" was a golden opportunity for me to leave a mark on my specialty. This gave me all the excuse I needed to fritter away many short days and long Swedish nights at the hospital musing about the challenge before me.

Whether through good luck alone or some combination of smarts, the concept of x-ray imageto-image correlation eventually dawned on me. The basic principle for frameless targeting that I envisioned utilized computers to compare in real time newly acquired simple digital $\mathrm{x}$-rays with a patient's prior CT scan. It was this technology that would someday prove key to creating the future CyberKnife. Clearly being immersed in the Karolinska Institute's world of stereotaxis reinforced whatever independent insight I had. Over time the idea made more and more sense to me, especially given the emerging computer revolution. That said I had absolutely no appreciation for what would be required to realize my concept.

I frequently wonder if my naiveté at the time was actually a blessing. Without a serious mentor, the arduous process of making frameless radiosurgery a reality was only slowly revealed to me, step-by-step, over 18 years. Had I realized beforehand what would be involved in building Accuray, Inc., I'm not sure I'd have chosen the path I did.

\section{$\ell$ Lesson $\ell$ It is near impossible to prepare oneself for the emotional demands required to start a serious new company, so perhaps a little naiveté isn't necessarily bad}

\section{Serendipity or destiny?}

Serendipity proved a significant influence throughout much of my Harvard residency. Between my neurosurgical rotations at Massachusetts General and the Brigham and Woman's Hospital, I was peripherally involved in Ken Winston's breakthrough development of the first linear accelerator (LINAC) based radiosurgical system, and Ray Kjellberg's groundbreaking work in 
Proton beam radiosurgery. Quite by accident, I had by the end of residency experienced much of the most important work going on anywhere in the newly emerging world of radiosurgery, and was in many ways already an expert. This background, combined with my incipient interest in frameless targeting, made me all the more determined to pursue a subspecialty in radiosurgery into my postgraduate life. Without much deliberation, I set out towards what would become a lifetime pursuit. The truth is I simply fell into my vocation.

Today I am convinced that Stanford University and the San Francisco Bay Area is about the only place in the United States where one could start a company from scratch that utilized therapeutic radiation. The microwave source used to power the $\mathrm{x}$-ray-producing linear accelerators was developed during the Second World War in the high-energy physics labs at Stanford. Then in the 1950's, this knowledge was transferred to the Varian Corporation in Palo Alto, which to this day remains the dominant company in the world of radiation therapy equipment. The early presence of this technology at Stanford was critical to making Hodgkin's disease the first form of "curable" cancer in the 1960's. Many other irreproducible resources in the Bay Area, such as the federally-supported Stanford Linear Accelerator (SLAC), Lawrence Berkeley Labs, and the world headquarters for Siemens Radiation Oncology, made it an ideal location for a business involving high-energy radiation. Nevertheless, I had almost no idea of how unique an environment I was entering when I accepted a job at Stanford's Palo Alto Veteran's Administration Hospital in 1987.

The academic goal I set for myself upon coming to Stanford as a junior faculty member was to build a "frameless" radiosurgical device based on my original concept of x-ray image-to-CTimage correlation. However, I had no guidance, no mentor and no real understanding of how to go about the task at hand. My own educational background had given me limited exposure to the type of technology to which I clearly needed access. On the other hand, I had considerable experience, relatively speaking, with the emerging clinical application of radiosurgery, a project for which I found ready support from Stanford Hospital and the Departments of Neurosurgery and Radiation Oncology. While not directly related to my objective, the steadily growing radiosurgery program that I built gradually at Stanford over many years proved critical to the eventual clinical validation of Accuray's technology.

\section{$\ell$ Lesson $\&$ Chance may favor the prepared mind, but it is also better to be lucky than good.}

\section{Getting started}

My first efforts at technology development began in conjunction with Tom Binford, a professor of machine vision in the School of Engineering at Stanford. I wrote a small institutional grant that was funded by the NIH, with which I paid a computer science graduate student who, as part of his thesis, investigated algorithms for image correlation. With limited funds, all we could do was simulate with biplanar fluoroscopy what a dedicated x-ray imaging system might deliver. Based on this research, we concluded that an approach based on feature recognition would accomplish the job at hand. In hindsight, I realize that this technical conclusion was hopelessly naïve, but as long as I believed, rightly or wrongly, that the technology could be made to work, I kept pushing forward.

While this research was being conducted, I met a former meningioma patient in the VA clinic who happened to be a SLAC physicist. I discussed my vision for a frameless radiosurgical system with him. At that point, I had come to believe that a robotic device for aiming the radiation beam would complement the flexibility of target localization. An obvious impediment to such a concept was the enormous size and weight of the standard medical linear accelerator. Two weeks after our introduction, I received a visit from my new patient, brochures in hand depicting a small, ultra-light-weight linear accelerator, the manufacturer of which was only 15 


\section{Cureus}

miles down the freeway in Santa Clara. My patient's forceful "can do" attitude resulted in a meeting with the appropriate group of engineers at Schonberg Engineering (former Varian and SLAC engineers), and with this introduction I saw for the first time how all the components of an eventual CyberKnife might come together. Within a few months time, I applied for two State and Federal (NIH-SBIR) research grants to further the development work of my Stanford engineering team. As part of the grant application process, I commissioned the first concept drawings for my new contraption. Fifteen years later, it is interesting to reflect on the durability of some of those design elements, despite the then-primitive understanding of all the technology that needed to be developed (Figures 1,2). With the funding provided by these grants, work on the future CyberKnife began in earnest.

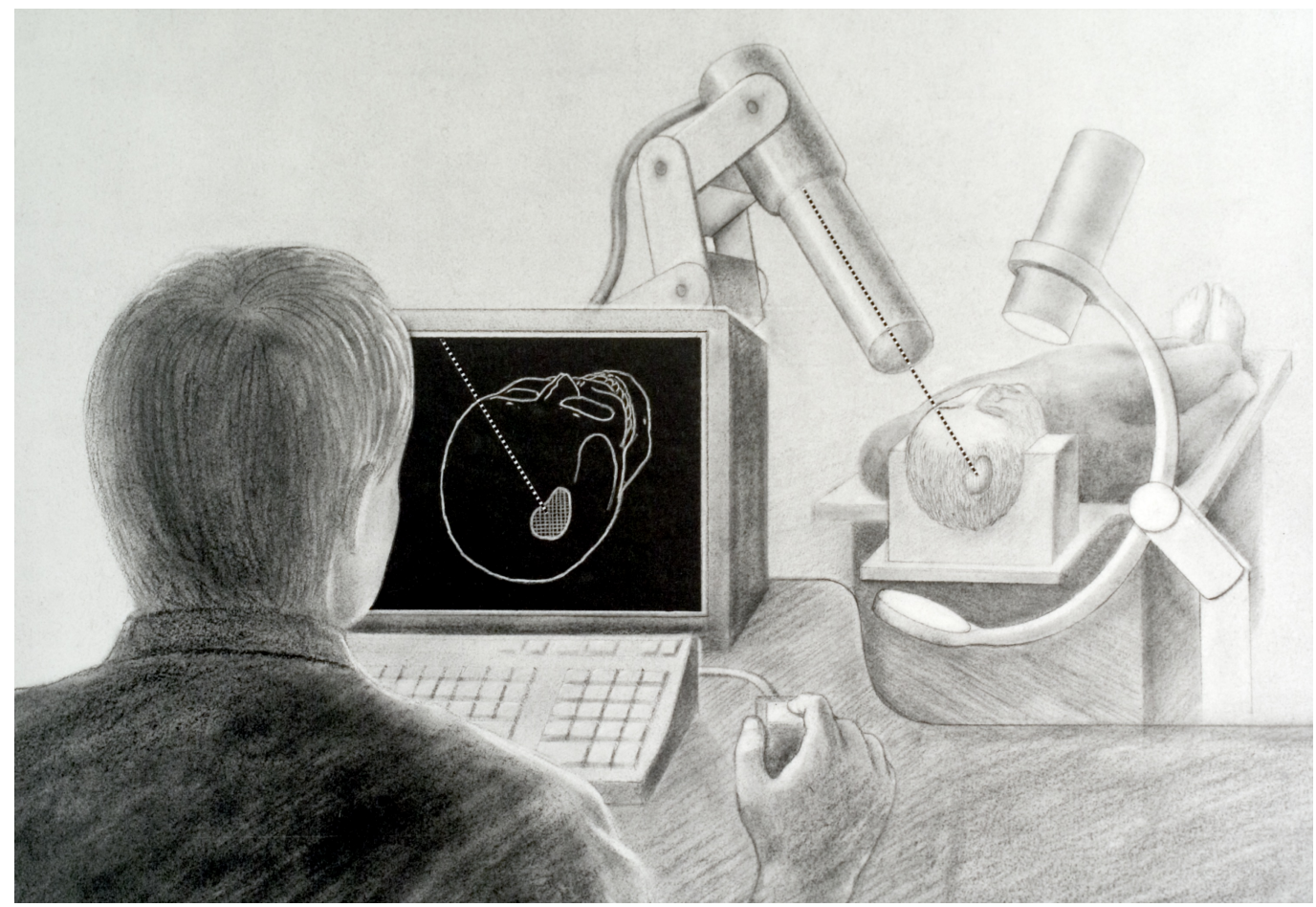

FIGURE 1: Made in 1988 this image depicts the initial concepts of the frameless radiosurgical technology which would eventually become the CyberKnife 


\section{Cureus}

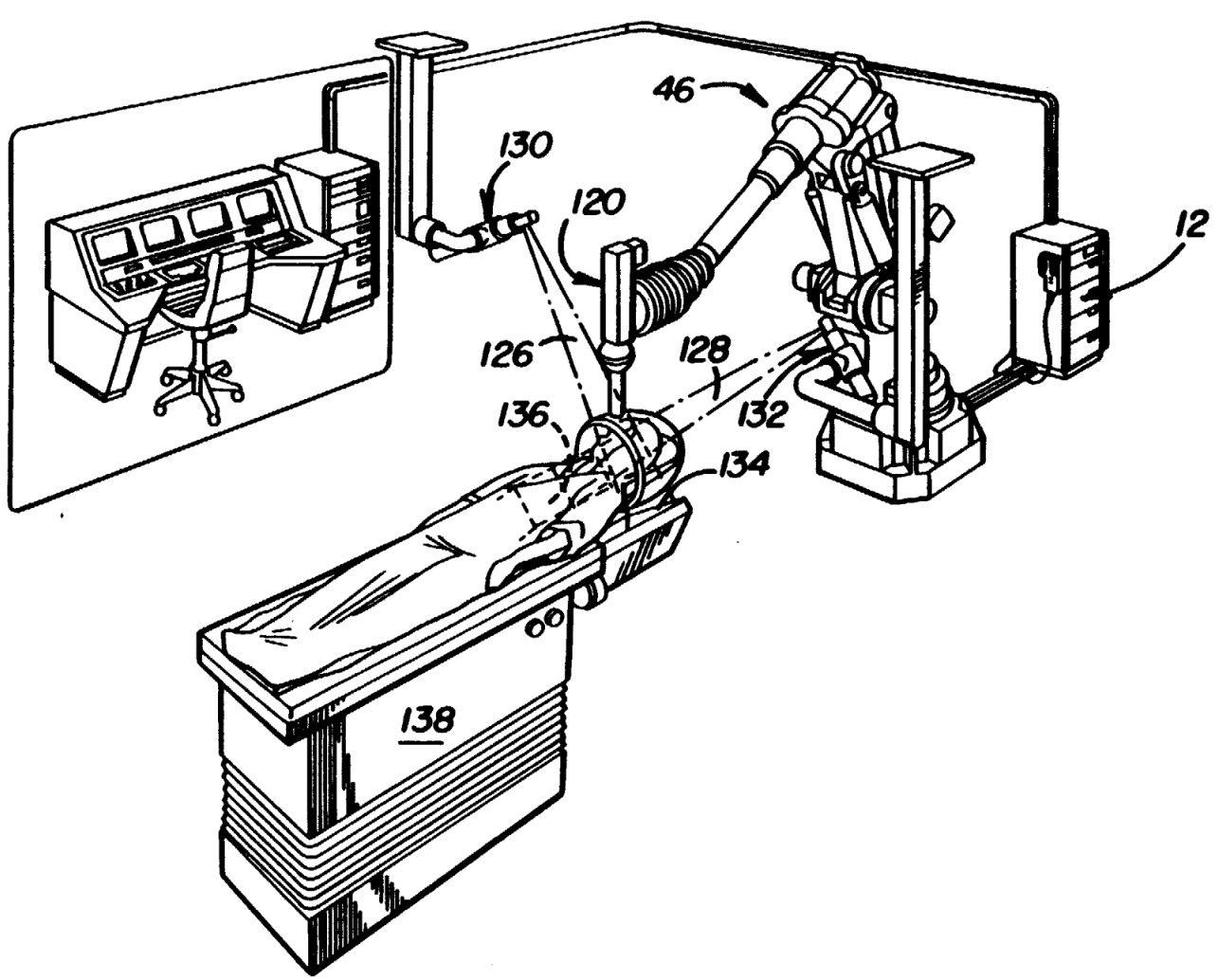

FIGURE 2: Included in my application entitled Apparatus and Method for Performing Stereotaxic Surgery that resulted in US

Patent 5,207,223

\section{Time}

Ideally, the intellectual foundation of a medical technology company parallels and even reinforces one's academic and clinical practice, which if possible, creates synergies in terms of time management. Given the close alignment between my clinical subspecialization and commercial ambitions, I was reasonably fortunate in this regard. Nevertheless, the process of creating a company takes time, lots of it. Without the necessary commitment of time, new innovations and businesses never happen. Like most young physicians, and especially neurosurgeons, I desperately wanted to build my clinical practice and put all my years of residency toil and newly acquired skills, to good use. Being a product of a gung-ho surgical culture my entire educational and professional life, I still blindly aspired to be among the busiest of neurosurgeons, even dreaming that I might become one of those overworked internationally renowned clinical work horses. Whether that could have ever been within my skill set, I will never know, for dream as I might, I was a junior faculty member and an employee of the United States Veterans of America Hospital System. Try as I might, I was only able to build the most modest of clinical practices within the VA. Since great clinical neurosurgical careers are rarely based on filling out patient disability forms, I was forced to turn my considerable energies elsewhere. Had I been more disciplined in my entrepreneurial pursuits, I would have recognized the need to make an intelligent compromise in my work life and not pursue a busier clinical practice. Lacking such insight, how fortunate I was to have an intense 
passion for creating something that would one day be termed called "image-guided radiosurgery" just waiting the fill the clinical void.

\section{$\ell$ Lesson $\ell$ Find time to remove yourself from day-to-day clinical responsibilities, but short of that, when life gives you lemons, make lemonade.

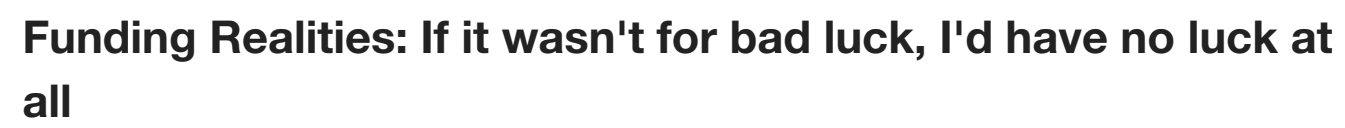

By 1989-90, I had come to believe (still somewhat naively) that many of the technologies for a frameless radiosurgical system might actually work. But developing the CyberKnife was going to take a lot of money, and I wasn't sure where my little research team would get it. I called the Head of the NIH Radiation Study Section, John Zimbrick, to discuss my ambition and the need for substantial funding. Zimbrick confided that the NIH was unlikely to fund such a project and suggested working with industry. So I spent a few months getting nowhere with the industrial partners that seemed like a logical fit with my goals. Each of those companies bluntly told me that my project involved too much basic research to be of interest and to go back to the NIH for feasibility funding. Meanwhile, none of the bigger government grants for which I had applied was funded. Reviewers, who I suspect were largely radiation physicists, typically asked, "Why would anyone want to fractionate radiosurgery/precision radiation," and "Why would anyone want to use such techniques to treat non-brain lesions?" This situation seemed implacable when, out of the blue, I was contacted by a semi-retired venture capitalist who was trolling through recently rejected Federal grants that had been submitted by Stanford faculty. This venture capitalist was convinced that my concepts could provide the basis for a company dedicated to commercializing frameless radiosurgery. Lacking other means of funding my project, I agreed to his suggestion, and despite innumerable setbacks over many years, have not deviated from this path.

Subsequently, my venture capitalist mentor dragged me and my concept drawings around to a small number of potential angel investors, some as far away as New York City. Although my presentation skills improved with practice, my vision for a frameless radiosurgical system fell on deaf ears. In contrast, many of the skilled engineering and managerial professionals with whom I was now regularly coming into contact through my work at Schonberg Radiation were quite enthusiastic about seeing my little dream commercialized. Given their opportunity for personal gain, I should not have been surprised, but at the time I was completely blind to such motivations and their enthusiasm was both flattering and motivating. Then, through a chance encounter at a neurosurgical colleague's house, I met an experienced, newly retired venture capitalist (and a major Stanford booster), Frank Lodato. Over the course of an evening discussion, Frank came to believe in the potential commercial value of a device that could perform frameless radiosurgery. During the ensuing weeks, I introduced him to some of the key technical people at Schonberg Radiation and he in turn started to make informal inquiries of his many friends within the Silicon Valley venture capital community. In relatively short order, Frank personally funded a patent submitted by me for "Frameless Radiosurgery," (just prior to my poster presentation at a Congress of Neurological Surgeons meeting) and convinced three of the most respected healthcare venture capitalists in the country to hear about our proposed company, Accuray, Inc. My wife, Marilyn, created the name after being inspired by a local auto maintenance shop called Accu-Tune.

Without too much deliberation or sophistication, I put together a team of engineers and managers, nearly all of whom were contacts from my association with Schonberg Radiation, to provide leadership for the proposed new company. I would remain on the faculty at Stanford and function as Chief Medical Officer for Accuray. Among American universities, Stanford has 
been permissive in this regard as long as "direct involvement" (the definition of which was quite liberal at the time) in the business was less than one day per week. With this primitive organizational structure and an equally primitive business plan and presentation, Frank brought our newly-assembled team before his big-name contacts in the venture capital community. Despite our best efforts, we struck out one-by-one; each and every venture capitalist failed to appreciate the potential clinical value of our technology and was, perhaps, even more disillusioned by its "capital equipment" nature. Unfortunately, when we were trying to sell our Accuray business plan, the venture capital community was beginning a ten-year love affair with medical device start-ups based on anything disposable, and our multi-million dollar system was inherently not disposable. Perhaps the potential investors didn't grasp the concept, or thought that the device would take too much time to catch on to become a commercially feasible product, or that the potential market was too small to provide a sufficiently fast payback (the reported benchmark that venture capitalists strive to earn is a minimum of five times their investment in five or fewer years!). In any case, having been rejected by some of the biggest venture capitalists in Silicon Valley, the ever-experienced Frank Lodato informed the Accuray team that we had, in effect, poisoned this potential financial well and there was essentially no chance of obtaining venture capital funding. His dire prediction proved all too true.

\section{$\ell$ Lesson $\ell$ Start small and stay focused because trying to get venture capitalist funding often takes a lot of dumb luck.}

\section{Neurosurgeons as investors}

Rather than give up on the Accuray dream, I reasoned that it might be possible to start a company by recruiting a group of neurosurgeons to serve as "angel" investors. It seemed possible that, by virtue of their professional backgrounds and often times not-inconsequential incomes, neurosurgeons may both readily understand the clinical value of my proposed technology, and have the means to make a meaningful investment. With this objective in mind, a management team that somewhat haphazardly coalesced around this project and I set out to fund Accuray through a limited partnership. It should be noted that in 1990, as we were trying to secure funding, I was the youngest founder by nearly 15 years. Because I had so little experience in the start-up world, I was rather insecure about my position. Furthermore, I was flattered by all the attention my idea was getting from what seemed to me to be a relatively seasoned group of engineers and managers. In hindsight, I should have been much more forceful in shaping our emerging team, and much tougher in negotiating my portion of the equity split. Nevertheless, I set out to fund Accuray Limited Partnership.

Although I was only one of many founders of Accuray, Inc., and was by far the youngest and least experienced businessman, the task of raising money somehow landed squarely on my shoulders. Unfortunately, the first Gulf War was just starting and a severe U.S. recession was setting in, circumstances in which it is never easy to raise money. While I attempted to solicit $\$ 100,000$ each from several dozen neurosurgical and non-medical friends and their business associates, I was only able to collect commitments of a little more than $\$ 600,000$ toward my initial $\$ 2$ million goal. (There was a clear correlation between the strength of my friendship with an individual and my ability to raise money from them.) Having run out of qualified friends, however, it was obvious even to someone with my limited start-up experience that this level of funding was inadequate to move forward. Nevertheless, in the process of raising money, several individuals who declined to invest personally expressed an interest in convincing their hospitals to buy our technology if we built it. With this insight and more than a little pluck, we set out to sell to a few select hospitals a frameless radiosurgical device, which would soon be called the CyberKnife, simply based on a set of concept drawings.

\section{$\ell$ Lesson $\ell$ Don't underestimate the value of the Three Fs:}




\section{friends, fools and family \\ One fast-talking salesman}

Given the current financial circumstances of hospitals, it now seems inconceivable that a thoroughly untested new company without credible financing might be successful selling a yetto-be-created multi-million dollar medical technology. However, 1991-1992 was a very different time, and I was too determined and too dumb to know better. Given the thriving LINAC-based program I had developed, Stanford University Medical Center became an obvious first customer. It was a long and complex process convincing Stanford Hospital administration to become customer number one, until a friend helped me secure a major pledge from a Saudi sheik to back the project. Pledge in hand, the Hospital agreed to move forward. Their commitment to buy a Neurotron 1000, as our radiosurgical technology was initially called, was accompanied by an upfront payment of $\$ 250,000$. With that check in hand, and additional funds from "Friends of John," as the investors in our limited partnership came to be nicknamed, Accuray rented modest office space in the heart of Silicon Valley (just across the street from the corporate headquarters of Silicon Valley legend Intel) in January of 1992 and commenced operations. Through a sundry web of neurosurgical contacts, it wasn't much longer that the new CEO and I sold a second system to a privately-owned imaging center in Southern California. This early sale was clearly vital to making a "go" of the business. However, given the obvious financial risk, the deal included special financial considerations and distribution rights that would come to haunt the business for many years to come.

\section{$\ell$ Lesson $\ell$ Beggars can't be choosers, but beware of "Faustian" deals}

The sale of a second Neurotron 1000 also included generous progress payments, which were once again used to sustain company operations. Soon a part-time East Coast sales consultant joined our effort, and over the next six months four more Neurotron 1000s were sold across the United States, including several to big academic centers. Each deal included a down payment and commitment to make progress payments as certain technical and production milestones were met. I renamed the product the CyberKnife, and soon business appeared to be booming. After such a long wait, my frameless radiosurgical technology finally started to come together.

\section{Putting CyberKnife to the test}

Over the first year of its operation, Accuray rapidly validated many of the core technologies that underlie the current CyberKnife. However, with marginal funding the research and development effort was superficial at best. We didn't even have the money for a radiationshielded facility in which we could test a completed system. Instead, component parts, which had only undergone the most preliminary testing, were shipped to and assembled at our first CyberKnife installation, Stanford University Medical Center. In the spring of 1994, a shielded bunker was completed in a newly-constructed ambulatory medicine building especially for this project. After resolving a myriad of technical, political and logistical glitches, which ranged from finding radiation-shielded space for the CyberKnife to concerns about my conflict of interest, and getting both an Investigational Device Exemption (IDE) from the FDA and Stanford IRB approval, we were ready to treat our first patient.

On the eighth of June 1994, an elderly woman with a solitary brain metastasis was treated with our frameless radiosurgical device (Figure 3). Because of numerous software bugs, the actual length of treatment required the better part of an afternoon. By most measures, frame-based radiosurgery would have been vastly simpler, but we had made the first clinical step. Unfortunately, the patient did not survive long enough to get a follow-up MRI scan, and the exact cause of her death was unclear. Given the complexity and unreliability of the CyberKnife, 


\section{Cureus}

the co-existence of a frame-based LINAC radiosurgical system at Stanford, and the untimely death of Rick Cox, a brilliant PhD medical physicist with whom I was working, I used my new technology sparingly at first, waiting desperately for the engineers to implement technical improvements. During the earliest days of the Stanford CyberKnife, no more than one patient per month was treated. Although it was never openly acknowledged at this time, many of my closest colleagues at Stanford viewed the entire project as "Adler's folly" and were convinced the CyberKnife idea would never get very far. In the face of such skepticism, it was a constant effort to stay optimistic. Much like being immersed in a craniotomy in which the situation seems increasingly hopeless, I forced myself to stay positive and kept putting one foot in front of the next.

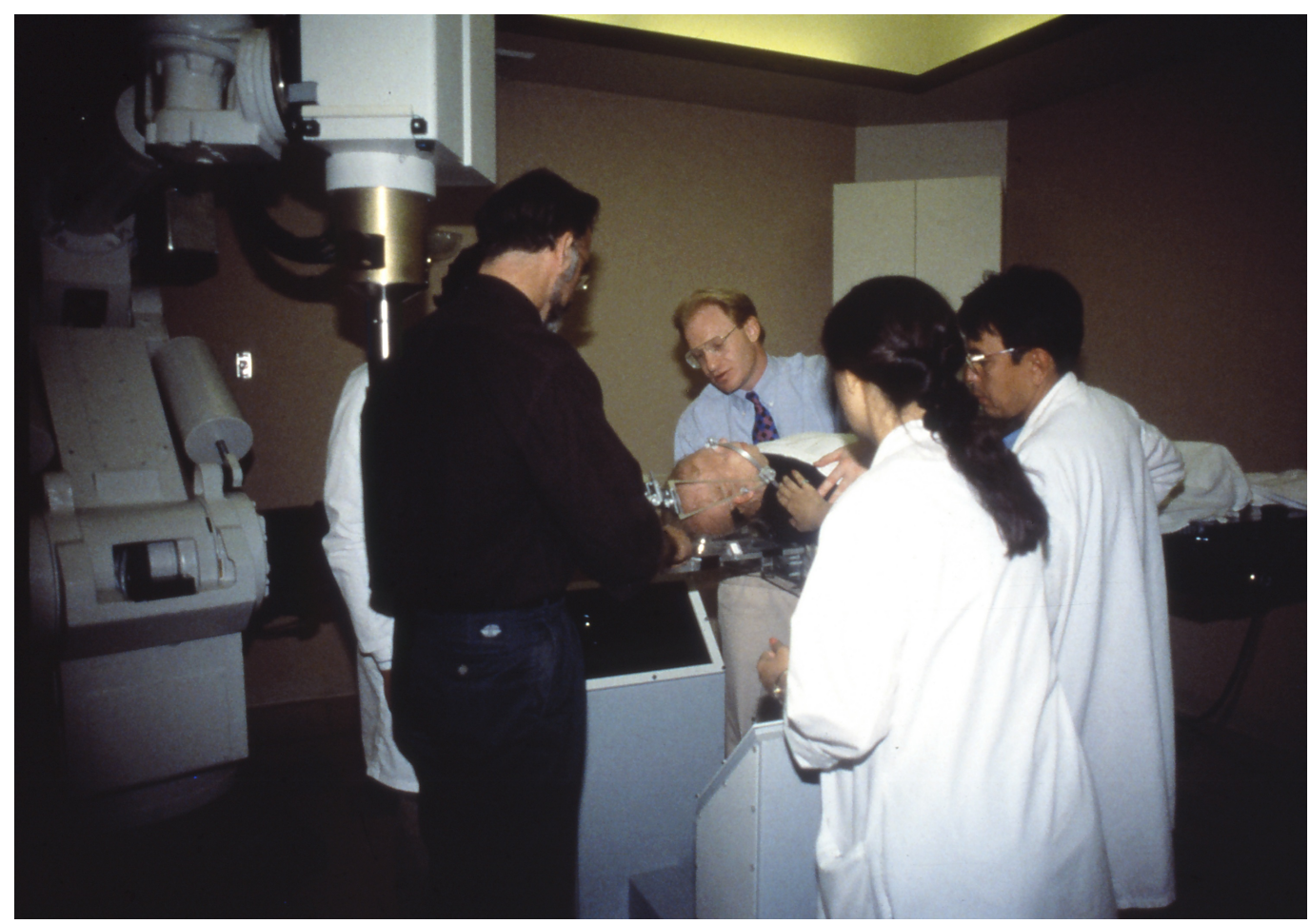

FIGURE 3: At the time of the first CyberKnife patient treatment on June 8, 1994

\section{Risky business; darkest hours}

Growing revenues are an important sign of a healthy business, but a truly successful company must also be profitable. Some start-up companies can sustain years of losses providing they have substantial financial backing, but Accuray was not so fortunate. The amount of funding we had attracted was laughable given the complex nature of the technology being developed. This would not have seemed like a looming disaster had the price to customers exceeded the CyberKnife's development and manufacturing costs (i.e., if we had a profitable business).

Meanwhile, my time was stretched to the limit between Stanford and Accuray. Although I was neither employed nor paid by Accuray, I was helping the company by performing several critical functions. I oversaw our flagship CyberKnife facility and was intimately involved from medical advisory, regulatory, marketing, sales, and technical research standpoints. I naively assumed that the experienced business and technical team I was working with would manage company operations, so I was blissfully unaware that the true costs of fulfilling the terms of our contracts greatly exceeded our sales price. Clearly this was a recipe for disaster, but the Company had repeatedly pulled one rabbit after another out of our financial bag of tricks, more often than 
not with my help. Despite living on the edge of financial disaster for several months, operations continued without interruption. But it was clear that as long as Accuray remained chronically under-funded, we were doomed.

While the Board of Directors sought a solution, I felt a deep sense of responsibility to both my friends who had invested in the Company and customers who had made major commitments based on my reassurances. Although I was extremely worried that the core ideas to which I had given so much effort might disappear, I somewhat naively trusted the more experienced team around me to find a way out of our financial problems. Believing that a major imaging company was interested in purchasing Accuray, our CEO led an all-out effort to broker a deal. There was unwarranted confidence among management and the Board that a combination of investors and customers, including a new Japanese distributor, would step up and fund the Company in the event we were not able to make a deal. The sad truth was that we had the most meager of bank accounts and no real Plan B. On Christmas Eve 1994, I was informed that our potential acquirer had backed out at the last minute. In the first week of the New Year, the company ran out of cash, and the CEO resigned. The same day, two-thirds of our employees were laid off. Led by a temporary CEO from the Board of Directors, the Company immediately embarked on a desperate scramble to find the money to keep the business alive. Over the next few months, they put together a bridge loan funded by a combination of reluctant customers and investors, who, despite misgivings, still believed in the product's concept and wanted to protect their prior investments. The next three years of Accuray's existence would prove little more than a continual struggle for survival, and was one of the most emotionally bleak, yet highly educational, experiences of my life.

Between 1995 and 1998, a small, intrepid team of Accuray employees, led by a seasoned medical-device CEO, fought to stay afloat with a meager bridge loan. Income from the manufacture and installation of four additional CyberKnifes provided badly needed cash. During those very lean years, Accuray's survival necessitated constant imagination and resourcefulness on the part of every employee. Despite incredible dedication and hard work on the part of the engineering team, the system performed poorly and did not meet customer's expectations. There just wasn't enough money to finish much needed engineering. Somehow, in the face of so many challenges, the staff remained loyal. Fortunately, small numbers of patients were being treated successfully under an IDE from the FDA, and incremental improvements were made to the technology, both of which resulted in a few academic publications. System modifications implemented by my Stanford research group allowed us to successfully perform image-guided spine radiosurgery for the first time. As originally envisioned when the company was founded, I led most of the technology and clinical research efforts at our flagship facility, Stanford University. Accuray's other founders rapidly disappeared; only true believers were able to hang onto the original dream after so much uncertainty and pain.

\section{\& Lesson $\&$ Hope for the Best, Expect the Worst}

During Accuray's years of bootstrapping, I participated in one company fundraising effort after another. Many of these involved contacts with common Silicon Valley sources of venture capital, but there were also a wide assortment of colorful individuals, many clearly charlatans, who came out of the woodwork allegedly interested in funding the company. In the face of years of non-stop hustle in the name of survival, I still naively aspired to live up to the Golden Rule. But before long I came to understand the well-known business truism, "He with the gold, rules!"

\section{Land of the rising sun}

Somewhat unexpectedly, our Japanese distributor, a subsidiary of a major trading firm, 
obtained government approval to market and sell the CyberKnife in Japan. This proved vital to Accuray's existence. Given the backing of their parent company, our distributor was able to put more substantial sales, marketing and service resources behind the CyberKnife in Japan than we could dream of doing in America. The distributor's commitment to sales, combined with the Japanese enthusiasm for high-tech medical equipment, especially anything robotic, generated considerable interest in the CyberKnife concept among potential Japanese customers. The early interest within the Japanese market proved critical to sustaining Accuray until it could rebuild the reputation of its U.S. product.

\section{\& Lesson $\&$ When there's brainstem function, there's life}

In March of 1997, Accuray was once again almost completely out of cash and without any credible prospects of such. Despite this dubious outlook, my longstanding neurosurgeon friend and early investor in Accuray, Jim Doty, decided to personally invest a significant amount of cash to keep the business alive (albeit not enough to rebuild the company). The company was reorganized and Jim became CEO after leaving his private practice in Southern California. As CEO, Jim dedicated himself to securing the critical and more substantial funding that Accuray needed if the company was to be anything more than one of the "living dead". Although I too was never far from the perpetual hunt for financing, I was now better able to focus my energies on the clinical R \& D work being conducted at Stanford. Accuray pursued a number of opportunities that proved to be blind alleys; again, we approached venture capital groups and a constellation of individuals and entities, nearly all of the latter merely masquerading as credible investors. Meanwhile, personal funds (Jim Doty's much more than mine) and some Japanese sales kept the company alive, but we were on life support. The company was on death's doorstep when another re-organization deal presented itself.

In 1998, a small, newly organized venture capital fund approached Accuray with a plan to invest. Two of its partners had previously worked as bankers, where they were introduced to Accuray in the course of considering an import-export loan intended to support our Japanese business. Although they lacked a background in healthcare, let alone experience in medical devices, the partners liked the CyberKnife business concept. Unlike the other more experienced venture capitalists we had approached over the preceding eight years, this contrarian group was not put off by our medical capital equipment focus. They also had extensive experience working with distressed companies, an apt description of Accuray's condition; heavily in debt and saddled with several ill-conceived contractual obligations. Lacking other credible suitors, an April Fool's Day deal (which proved to be anything but) was fashioned to re-organize the company around an initial large loan, to be followed by an infusion of equity the next year. Relative to comparable technology companies, the amount was modest, but compared to prior investments in Accuray, it was huge; it allowed the company to move from abject poverty to the lower middle class. At the same time and perhaps equally important, CyberKnife sales were beginning to grow in Japan. Thus, Accuray had the capacity to make a meaningful investment in product development and service for the first time in five years.

In the year following Accuray's re-organization, debts were repaid, contracts were renegotiated and number of employees were hired. Furthermore, with a huge company-wide effort, the CyberKnife was granted 510K Clearance by the FDA to begin sales and marketing in the U.S. But Accuray still lacked the financial resources to put together a serious sales and marketing campaign. With me driving the clinical research effort at Stanford (in particular, attempting to begin a program in intra-abdominal and thoracic radiosurgery), CEO Jim Doty went solo to restart US sales. Given Accuray's history and the precarious nature of our finances, the latter proved a very hard sell. As a consequence, Jim and I believed that Accuray's success depended on attracting deeper financial backing. With this goal in mind, Jim turned his efforts to bringing in new, well-heeled investors. In the process, the venture capital team that saved Accuray the year before became alienated. They believed that Company sales should in 
themselves be sufficient to fund operations and grow the business. After several contentious board meetings, Jim, much to my chagrin, resigned both his CEO and Board positions.

\section{^ Lesson $\ell$ Rich or not, survival depends on pulling together}

Jim's departure was a blow to our fragile company. While the operational progress of Accuray during the two years of Jim's tenure had been modest, it was the most significant momentum we'd experienced in years. Our business was unusually complex and finding the right outside leader would be critical but also unusually long and difficult. Many key employees had put up with a lot of grief over many years, and I feared an exodus of talent from which the company might not recover. Although I lacked first-hand management experience, I was confident that I understood the technology and the market better than anyone else. With little deliberation, I organized a Leave of Absence from Stanford and assumed the role of Chairman and CEO at Accuray, and thus began the next stage of my business education.

\section{Baptism by fire}

When I took over as CEO of Accuray in September 1999, the company had little cash remaining from the most recent round of financing, there were no serious prospects for new U.S. sales, and the credibility of our flagship U.S. CyberKnife was undermined by my decision to become more fully involved with Accuray. It necessitated heroic efforts from my neurosurgical colleagues, and me, often trying to be in two places at one time, to keep Stanford's clinical program creeping forward. Furthermore, the CyberKnife was deemed terribly unreliable and therefore underutilized at every other U.S. facility, which made for poor customer references. To compound the problem, the FDA clearance described a product that had yet to be shipped, so treatments could only be done under the original Accuray-sponsored IDE, which was a paperwork nightmare. A critical component of the system, the amorphous silicon cameras, were either defective or available in such limited numbers that it was a major challenge to deliver on the few critical sales being made to Japan. If all this wasn't bad enough, key managers were at each others throats and Company morale was at a new low fueled in part by the turmoil at CEO. Moreover, during the 1999 Silicon Valley employment boom, it was virtually an article of faith among many vital employees that almost anyone could join a startup down the street and in a few years be worth millions.

My welcome upon becoming CEO was frosty at best. The general feeling at Accuray was that, founder or not, another neurosurgeon had no business running a Company with 60-plus employees. In their eyes, a professional CEO was long overdue. But what capable CEO would climb aboard our sinking ship? Unlike the seasoned manager they were hoping for, I was too naïve, passionate and maybe vain to abandon the CyberKnife idea.

\section{\& Lesson $\&$ Founder: only mothers give out unquestioning love!}

\section{No time to stand still}

It wasn't all bleak. Most of our customers remained believers in the CyberKnife concept, even if they were disillusioned by the Company's execution. There was still a core group of brilliant, hard-working engineers and managers who were committed to making the Company successful despite the allure of all the technology start-ups in Silicon Valley. And the situation was considerably brighter in Japan. Our initial customer there was extremely busy performing imaginative procedures and served as an excellent local customer reference. We also had a small number of Japanese sales in the pipeline, and our distributor there was prepared to invest a lot more if we could survive. These successes were sufficiently heartening to keep the Company pushing forward. 
The culture of business is miles apart from the world of a neurosurgeon. Over time I learned about such things as annual budgets, inflated sales projections, management termination agreements, revenue recognition, quality assurance, FDA audits, marketing expenses, vendor quality audits, cost controls, stock options, S-1 IPO registration, and an entire range of buzz words that were foreign to my familiar world of academic neurosurgery.

\section{$\ell$ Lesson $\ell$ If you can't convince 'em with brilliance, do your best to muddle through.}

Although I asked a lot of questions of the experienced $\mathrm{COO}$ about how to run a complex business, I was self-conscious about appearing naïve and fearful of undermining what little credibility I had in the eyes of my soon-to-be 90 employees. Nevertheless, I felt strongly that I knew how to move the platform CyberKnife technology forward, and prodded the organization to get us moving in that direction. In the process, several key employees who never seemed to embrace my vision ended up leaving the company. With lots of hard work, upgraded and FDAcleared CyberKnife systems were installed at our U.S. sites and product reliability improved. More patients were being treated around the world, and this led to the publication of additional scientific reports further validating the clinical application of CyberKnife technology. Accuray even moved forward with a research project whose goal was to dynamically track lesions that move throughout the respiratory cycle. On the financial front, a very small series A financing, backed in part by a handful of friends, combined with growing sales in Japan, gave the company a little bit of financial wiggle room. Despite our hand-to-mouth existence, the cumulative effect of these changes was to reinforce the viability of the company in the eyes of employees and customers.

\section{You can make it, but can you sell it?}

With FDA clearance, an improved product and one respectable U.S. clinical reference site (Stanford), Accuray resumed U.S. sales in 2000. We formed a rudimentary sales team consisting of a part-time consultant and one full-time sales rep. Like many other decisions I would make as CEO, this initial team ultimately did not work out well. But I was usually was able to recognize my mistake before too much damage was done and find a way to rectify the situation. My involvement in sales proved vital to the process. I had personal access to many surgeons, especially neurosurgeons. Even more importantly, I proved uniquely able to articulate to customers and investors the future of our technology and how it fit into the emerging world of extracranial neurosurgery. In addition, given a paltry marketing budget, my attendance and speaking engagements at major neurosurgical and radiation oncologic meetings worldwide became an important part of our sales strategy. Early on this was the only marketing effort our company could afford.

Reinvigorating U.S. sales proved harder than expected, and in the end required some unconventional deal making, beginning with our flagship facility. After a protracted, complex and delicate negotiation with Stanford Hospital, they agreed to buy an upgraded, FDA-approved version of the CyberKnife at a heavily discounted price. While the discount was necessary to restart U.S. sales, it would be the last time Accuray would to resort to such a sales strategy.

As the Stanford deal was being consummated, I hired a fearless experienced and hard charging head of sales and marketing. Although my decision upset a number of employees, the new VP quickly revamped Accuray's sales processes and taught me what was required to make big deals happen. Soon thereafter, a simmering Georgetown deal was closed with the help of a third party, which assumed much of the financial risk. Georgetown University had been an early customer, but rescinded the contract and requested the return of their downpayment after we failed to deliver a CyberKnife on time. Although we had no money with which to pay them back, we eventually did so, but only through considerable sacrifice. Unbeknownst to us at the 
time, the repayment preserved Accuray's reputation. Consequently, when we returned with the internal support of a former fellow resident who was now Chair of Neurosurgery, hospital administration was receptive. With Stanford and Georgetown deals in hand, it was safe to say that Accuray was finally back in the U.S. market, and the Company developed better sales processes.

Although we couldn't really afford it, I agreed to put on a big expensive exhibit at the 2001 American Association of Neurological Surgeons (AANS). This decision proved decisive in changing customer perceptions of Accuray; shortly thereafter several more contracts were signed, driven in part by a novel shared revenue plan the Company had created. Selling to each of the early customers required tremendous effort on the part of many company employees, but especially me. To close one prestigious account more than 30 sales-related trips were made. Several early customers were close professional acquaintances, and it appeared that they elected to buy in part because of our personal relationship.

\section{Is there dough in an IPO?}

Despite growing foreign and domestic sales, Accuray was not yet profitable and we badly needed more investment to survive. Because we lacked credible private equity or corporate prospects for funding, and because the U.S. stock market was still managing to take businesses public late in 2000, the Accuray Board of Directors elected to make a run at becoming a public company. At the time I knew this was not the best idea; not only was the process expensive and time-consuming, there were far too many uncertainties in our revenue projections to ever keep Wall Street happy. But like so many decisions the company had made in the past, this one was driven not by what was best for the business, but rather by the absence of a credible alternative.

Over a span of six months I lead a huge effort to make the company as presentable as possible, entice a team of underwriters, and generate the voluminous S-1 prospectus that would eventually define the terms of a public offering. In the spring of 2001, just two days before we were scheduled to file with the Security Exchange Commission (SEC), our Japanese distributor came back to the company with a new and significantly lower sales forecast. This news, combined with a now rapidly collapsing U.S. stock market, led the Board of Directors to pull the plug on an IPO.

IPO or not, Accuray still desperately needed new investment, and it was my job to find it. With the help of a team of investment bankers, we turned our efforts to funding the company through an equity private placement. Again, the timing was awful. The United States was sliding into a recession and investors in small start-up companies had suffered some of the worst losses in a generation, especially in Silicon Valley. Over a six-month period, the CFO and I traveled continuously trying to sell our deal. When it seemed that no one was interested, a major blue chip, East Coast venture capital fund stepped forward with a term sheet and an aggressive plan to finally fund Accuray. The offering price left a lot to be desired, but after more than ten years of effort, I felt some satisfaction in knowing that I had had finally succeeded in convincing a sophisticated and financially strong group of investors to back my idea. My sense of accomplishment didn't last long; Accuray's controlling investors rejected the offer, and in return, my discouraged CFO quit.

With a continuously improving product and sales picture going on in the background, our investors eventually concluded that they would lead the next round of Private Placement funding at a price of their choosing. Once more I had to repeat the arduous process I had just gone through. Painful or not, I did what I needed to do; I sold the deal to keep our business going. In parallel it was becoming increasingly clear to me that my greatest value to the company was not my negotiating skills, my financial contacts or my interest in managing people, but rather my skill as a clinical investigator. Even after my absence from Stanford, I 
remained the primary clinical spokesman for the CyberKnife. I believed in 2001, as I do today, that this role would be more important to the success of the Accuray, Inc.'s vision than any other of the CEO functions I was performing.

\section{\& Lesson $\&$ Jack of all trades and a master of none: Stick to What You Love}

After months of spirited discussions with my investors, I convinced them that Accuray had been stabilized and it was best for everyone, including the company that I return to my faculty position at Stanford. In concert with the new series $C$ round of funding, a formal search for a new CEO was conducted. I was delighted when in early 2002 the Board of Directors selected as my successor the sole candidate recommended by me and I could return to my full-time faculty position at Stanford.

Since stepping down as CEO in 2002, I maintain a close working relationship with Accuray, serving on the Board of Directors (until 2009) but more importantly, functioning as the unofficial chief clinical spokesman. Over the past seven years, sales have continued their upward trajectory and both the organization and product have grown in sophistication. While I find all of this exciting, the greatest rewards have come from seeing the accelerating numbers of non-brain patients being treated with CyberKnife radiosurgery throughout the world. No business can ever have complete confidence in what the future might bring, but it appears that my 18-year-old vision for the future of non-invasive surgery, is in good corporate hands and the best is yet to come.

\section{Conclusions}

\section{Epilogue}

Neurosurgeons endeavor to prolong the lives and relieve the suffering of our patients. Generally, this responsibility is fulfilled within the context of the standard doctor-patient relationship. A fundamental mission of academic neurosurgery, however, is also to create and examine new techniques and concepts for treating the next generation of patients. One can even argue that this pursuit is a moral imperative for medical academicians whom society rewards generously for this purpose. In many situations, the academic process of conducting research, analyzing data, and publishing papers is sufficient to improve the lives of patients. For example, such scholarly processes may benefit patients by producing an improved surgical approach based on a better understanding of anatomy or physiology. Nevertheless, when new technologies are at stake, it is apparent that society does not gain from a solely academic course of action. In the global economic world within which medicine operates, the challenge of extending the benefits of new medical technologies absolutely requires the involvement of forprofit enterprises. The above personal experience demonstrates that neurosurgeons have an important role to play in this process.

\section{$\ell$ End Lesson $\&$ For an academic neurosurgeon, a company is a means to an end; the vehicle through which new therapies can be delivered to improve the quality of our patients' lives.}

P.S. Don't do it for the money! The financial rewards of even a thriving medical device start-up are unlikely to be a sufficient incentive for most successful neurosurgeons.

\section{Additional Information}

\section{Disclosures}




\section{Cureus}

Conflicts of interest: In compliance with the ICMJE uniform disclosure form, all authors declare the following: Payment/services info: All authors have declared that no financial support was received from any organization for the submitted work. Financial relationships: John R. Adler declare(s) an alternate financial activity from Accuray, Inc. Founder and shareholder. Other relationships: All authors have declared that there are no other relationships or activities that could appear to have influenced the submitted work.

\section{Acknowledgements}

I want to thank Bonnie Hale and David Schaal for their invaluable creative and editorial assistance in writing this manuscript. 